\title{
Optical diagnosis of diminutive polyps in the Dutch Bowel Cancer Screening Program: Are we ready to start?
}

\section{다 (i)}

\section{Authors}

Alouisa J.P. van de Wetering1,2, Lonne W.T. Meulen ${ }^{*}, 1,2$, Roel M.M. Bogie ${ }^{*}, 1,2$, Quirine E.W. van der Zander ${ }^{1,2}$, Ankie Reumkens ${ }^{1,2,3}$, Bjorn Winkens ${ }^{4,5}$, Hao Ran Cheng ${ }^{6}$, Jan-Willem A. Straathof ${ }^{1,6}$, Evelien Dekker ${ }^{7}$, Eric Keulen ${ }^{3}$, C.M. Bakker ${ }^{3}$, Chantal Hoge ${ }^{1}$, Rogier de Ridder ${ }^{1}$, Ad A.M. Masclee ${ }^{1,8}$, Silvia Sanduleanu-Dascalescu ${ }^{1,2}$

\section{Institutions}

1 Department of Internal Medicine, Division of Gastroenterology and Hepatology, Maastricht University Medical Center, Maastricht, The Netherlands

2 GROW, School for Oncology and Developmental Biology, Maastricht University Medical Center, Maastricht, The Netherlands

3 Department of Internal Medicine and Gastroenterology, Zuyderland Medical Center, Heerlen, The Netherlands

4 Department of Methodology and Statistics, Maastricht University

5 CAPHRI, Care and Public Health Research Institute, Maastricht University Medical Center, Maastricht, The Netherlands

6 Department of Gastroenterology, Máxima Medical Center, Veldhoven, The Netherlands

7 Department of Gastroenterology and Hepatology, Amsterdam University Medical Center, Location Academic Medical Centre, Amsterdam, The Netherlands

8 NUTRIM, School for Nutrition and Translational Research in Metabolism, Maastricht University Medical Center, Maastricht, The Netherlands

submitted 5.8.2019

accepted after revision $\quad$ 18.11.2019

Bibliography

DOI https://doi.org/10.1055/a-1072-4853 |

Endoscopy International Open 2020; 08: E257-E265

(c) Georg Thieme Verlag KG Stuttgart · New York eISSN 2196-9736

Corresponding author

Alouisa J.P. van de Wetering, MD, Maastricht University Medical Center+, Division of Gastroenterology and Hepatology, PO Box 5800, 6202 AZ Maastricht, The Netherlands

Fax: +31-43-387 5006

w.vandewetering@maastrichtuniversity.nl
丹 Supplementary material

Online content viewable at:

https://doi.org/10.1055/a-1072-4853

\section{ABSTRACT}

Background and study aims Implementation of optical diagnosis of diminutive polyps may potentially increase the efficacy and cost-effectiveness of colonoscopies. To adopt such strategy in clinical practice, the Preservation and Incorporation of Valuable endoscopic Innovations (PIVI) thresholds provide the basis to be met: $\geq 90 \%$ negative predictive value (NPV) for diagnosis of adenomatous histology and $\geq 90 \%$ agreement on surveillance intervals. We evaluated this within the Dutch Bowel Cancer Screening Program (BCSP).

Patients and methods Endoscopic and histological data were collected from participants of the national bowel cancer screening program with an unfavorable fecal immunochemical test referred for colonoscopy between February 2014 and August 2015 at four endoscopy centers. The "resect and discard" scenario was studied, resecting diminutive polyps without histological evaluation. Agreement between optical diagnosis and histological diagnosis was measured for surveillance intervals according to Dutch, European and American post-polypectomy surveillance guideline.

Results Fifteen certified endoscopists participated in this study and included 3028 diminutive polyps. In 2,330 patients both optical and histological diagnosis were available. Optical diagnosis of diminutive polyps showed NPV of $84 \%$ (95\% Cl 80-87) for adenomatous histology in the rectosigmoid. Applying the 'resect and discard' strategy resulted in $90.6 \%, 91.2 \%, 90.9 \%$ agreement on surveillance intervals for the Dutch, European and American guideline respectively.

Conclusion Our data representing current clinical practice in the Dutch BCSP practice on optical diagnosis of diminutive polyps showed that accuracy of predicting histology remains challenging, and risk of incorrect optical diagnosis is still significant. Therefore, it is too early to safely implement these strategies.

\footnotetext{
* These authors contributed equally.
} 


\section{Introduction}

Colorectal cancer (CRC) is a major cause of cancer-related mortality and morbidity in the Western world [1]. To reduce CRC incidence and mortality, CRC screening programs have been implemented [2,3]. Screening via fecal immunochemical testing (FIT) is proven to be effective in reducing CRC-related deaths [4].

In 2014 the FIT-based Dutch Bowel Cancer Screening Program (BCSP) was implemented for individuals aged 55 to 75 years. After an unfavorable FIT result, patients are invited for a colonoscopy to detect and resect (pre) cancerous lesions. This has resulted in an increase in number of colonoscopies, polyp detection and resection and histological assessments, leading to a substantial financial burden on the health care system [5].

The majority of polyps found during screening colonoscopy are small $(\leq 10 \mathrm{~mm})$ and contain non-advanced histologic features, but in current clinical practice all polyps are resected and sent for histological assessment, on which surveillance recommendations are made. It has been seriously questioned whether histological evaluation of all these small, diminutive lesions is worthwhile and more efficient and cost-effective strategies should be implemented [6].

Optical diagnosis of colorectal polyps refers to "in vivo" estimation of histology of the polyp by endoscopists using high-definition endoscopy in conjunction with (virtual) chromoendoscopy [7]. Two strategies are proposed for implementation in clinical practice, but only if the Preservation and Incorporation of Valuable endoscopic Innovations (PIVI) thresholds are met [7]. First, the "resect and discard" strategy applies to diminutive $(\leq 5 \mathrm{~mm})$ colorectal adenomatous polyps which are resected, but are not sent out for histological evaluation (PIVI threshold: $\geq 90 \%$ agreement between optical diagnosis and histological diagnosis in determining the post-polypectomy surveillance interval). Second, the 'diagnose and leave' strategy, where diminutive hyperplastic polyps in the rectosigmoid are identified and left in situ (PIVI threshold: $\geq 90 \%$ negative predictive value (NPV) for optical diagnosis of diminutive adenomatous polyps) [8].

Up to now, data on optical diagnosis have been obtained mainly in study settings, i.e. from expert centers with highconfidence optical diagnosis, as the PIVI guidelines suggest. However, to actually implement these strategies, data from routine clinical practice are needed. Here, we present the first detailed data from the Dutch Bowel Cancer Screening Program (BCSP); a real-life but standardized endoscopy practice setting.

The aim of this study was to evaluate whether PIVI thresholds are met regarding a) the diagnostic accuracy of optical diagnosis for diminutive polyps and regarding $b$ ) the "resect and discard" and "diagnose and leave" strategy, within the BCSP in a defined region of the Netherlands, South Limburg, representing our national data $[9,10]$.

\section{Patients and methods}

\section{Patients and centers}

Longitudinal data collection was performed in the four endoscopy centers in South-Limburg region of the Netherlands: one academic center and three regional endoscopy units.

All endoscopic and histological data of FIT-unfavorable participants (55-75 years) who underwent colonoscopy within the context of the Dutch BCSP from February 2014 to August 2015 were collected. A threshold of $15 \mu \mathrm{g} \mathrm{Hb} / \mathrm{g}$ feces was considered FIT unfavorable (FOB gold, Sentinel, Milan, Italy) in the first six months but was raised to $47 \mathrm{Hb} / \mathrm{g}$ because of limitations in endoscopy capacity [5].

We included all patients with index colonoscopies fulfilling the quality criteria in the screening program (cecal intubation and adequate bowel preparation defined as Boston Bowel Preparation Score $[\mathrm{BBPS}] \geq 6$ ) in this retrospective analysis. This trial is registered in the Netherlands Trial Registry (NTR4844) and the METC of Maastricht University Medical Center assigned approval for the prospective colonoscopy database (Number: 14-4-046). Need for informed consent was waived by the Institutional Review Board.

\section{Endoscopists and equipment}

European guidelines for quality assurance in CRC screening have been set [3]. In the Netherlands, endoscopists have to be certified before being allowed to participate in the BCSP [11, 12].

To be admitted to the Dutch BCSP, endoscopists should have performed at least 300 colonoscopies and over 50 polypectomies per year. Furthermore, quality measures have been set and are evaluated [11]. In addition, endoscopists are required to register 100 consecutive colonoscopies with corresponding quality indicators. Then, a theoretical e-learning module should be accomplished and colonoscopic skills are evaluated in live practice setting and via videos [12]. All endoscopists in this study fulfilled the quality measures for the screening program as described above but they received no specific additional training regarding optical diagnosis of colorectal polyps.

Because the data are retrieved from a clinical practice setting, endoscopists performed standard care and were not informed about the study. All parameters currently included in the standardized endoscopy-report for the Dutch BCSP were obtained, assuming that all lesions found have been described in this report, as this is current clinical practice.

Among others, location, size, Paris-classification and predicted histology (optical diagnosis) were reported and the removed polyps were collected and sent in for histological evaluation. The classification options for estimated histology were: adenomatous polyp, hyperplastic polyp, sessile serrated lesion, carcinoma and other. No specific classification system (NICE, WASP) nor the confidence of the estimated histology are included in the standardized endoscopy-report. Therefore, these data were not available for evaluation.

High-definition white light colonoscopy (HD-WLE) was used in all endoscopy units and also (virtual) chromoendoscopy was available and used upon discretion of the endoscopist. All colo- 
noscopies were performed using endoscopic equipment containing virtual chromoendoscopy, either I-scan (Pentax Europe) used in one endoscopy unit or NBI (Olympus, Tokyo, Japan), used in the three other endoscopy units. The use of image-enhancement was not systematically included in the endoscopy report. To obtain an estimation on the use of image-enhancement endoscopy (IEE), we reviewed the photo documentation to see whether image-enhancement was captured in the photos. The use of IEE is scored for every polyp, and in case no photo was available or in case of more polyps in the same region, there had to be at least five (consecutive) photos where IEE was used for a positive score.

\section{Colonoscopy}

Standard bowel preparation regimens were used with polyethylene glycol solution containing ascorbic acid or Picosulfate sodium (Moviprep Norgine GmbH, Marburg, Germany or Picoprep ${ }^{\circledR}$, Ferring $\mathrm{GmbH}$, Kiel, German y). After introduction to the cecum, the quality of bowel preparation was scored using the Boston Bowel Preparation Score (BBPS), where 3 is the maximum score for each segment (right, transverse, left) resulting in a total maximum score of 9 [13]. BBPS score of $\geq 2$ for each segment and $\geq 6$ in total is considered adequate bowel preparation.

\section{Histology}

All resected lesions were sent to the local pathology department and processed according to standard protocol. All pathologists had been trained and authorized for participation in the BCSP [11]. The Vienna criteria for gastrointestinal epithelial neoplasia were used for classifying the biopsies, and the diagnosis by histology was used as reference [14].

\section{Outcome measures and statistical analysis}

The outcome was the diagnostic accuracy, i.e. overall accuracy, sensitivity, specificity, NPV and positive predictive value (PPV) between optical diagnosis and histological diagnosis of diminutive polyps, where histological diagnosis was used as reference standard. All polyps $\leq 5 \mathrm{~mm}$ with both optical diagnosis and histological evaluation were included in the analysis. To clarify the results, the data were dichotomized into in adenomas versus all other polyps and hyperplastic polyps versus all other polyps. Cross tables were made allowing to calculate the overall accuracy (percentage of congruent pairs), sensitivity, specificity, NPV and PPV.

To take into account use of IEE, a sensitivity analysis is performed, using Chi-square test, for the use of IEE and optical diagnosis.

To analyze whether diagnostic accuracy differs between the endoscopy units Chi-square test was used. We performed a sensitivity analysis to measure the effect of clustering (i. e. multiple lesions per patient), by calculating the values of the first primary outcome with and without multilevel correction.

The other outcome parameter was the post-polypectomy surveillance intervals based on optical diagnosis, according to a) Dutch Surveillance Guidelines [15] b) European post-poly- pectomy colonoscopy surveillance guidelines [16] and c) American Guidelines for surveillance after polypectomy [2].

Surveillance intervals were determined per patient based on a combination of optical diagnosis (for diminutive polyps) and histology, where histology was used as reference. For each individual patient, all lesions (diminutive but also larger lesions) were taken into account when determining the interval of surveillance.

These outcomes are chosen to evaluate whether two strategies can be implemented in clinical practice. The PIVI threshold for implementing the "resect and discard" strategy is $\geq 90 \%$ agreement between optical diagnosis and histological diagnosis in determining the post-polypectomy surveillance interval. For implementation of the "diagnose and leave:" strategy the PIVI threshold that should be met is $\geq 90 \%$ NPV for optical diagnosis of diminutive adenomatous polyps.

Statistical analyses were performed using IBM SPSS Statistics for Windows Statistical Package for Social Sciences (version 22, IBM Corp, Armonk, New York, United States) and R-statistics was used for the sensitivity analysis (R Foundation for Statistical Computing, Vienna, Austria).

\section{Results}

\section{Patient characteristics}

Between February 2014 and August 2015, 2,470 participants in the Dutch BCSP with an unfavorable FIT result underwent an index colonoscopy with polypectomy in the South Limburg region. A total of 140 cases were excluded due to insufficient colonoscopy quality (no cecal intubation [ $n=51$ ], inadequate bowel preparation $[n=19]$ or both $[n=70]$ ) ( Fig. 1 ), resulting in 2330 patients eligible for this study. In $>$ Table 1 characteristics of the included patients are described.

Fifteen endoscopists participated in this study ( $n=5$ from the academic center, $\mathrm{n}=10$ from regional endoscopy units). All had extensive colonoscopy experience (endoscopy experience in years: mean 10.9 years, SD 5.7; range 3 to 22 years) and had been certified for the national CRC screening program. The number of BCSP colonoscopies performed per endoscopist in the current study varied (mean 165 colonoscopies, SD 119; range 11 to 363 ).

\section{Lesion characteristics}

In total, 7,369 polyps were found; 1,573 were $>10 \mathrm{~mm}$ and 2,304 with size 6 to $10 \mathrm{~mm}$.

From the total of 3,492 diminutive polyps, both optical diagnosis ( $\mathrm{n}=196$ missing) and histological data ( $\mathrm{n}=160$ missing) needed to be available ( $n=108$ both missing), resulting in 3028 diminutive lesions that were included (> Fig.1). Endoscopic characteristics of these polyps are shown in $>$ Table 2 . Median size of diminutive polyps was $4 \mathrm{~mm}, 40 \%$ of the polyps were located in rectosigmoid $(n=1222)$. Histology showed that $67 \%$ were adenomatous and $19 \%$ hyperplastic. In the 1 - to $5-\mathrm{mm}$ group, a total of three carcinomas were detected and 15 adenomas showed high-grade dysplasia ( $>$ Table 2 ). 
2470 participants in the Dutch BCSP in South Limburg with index colonoscopy (Feb 2014 - Aug 2015)
140 patients excluded
- No cecal intubation (51)
- Inadequate bowel preparation (BBPS $\geq 6$ ) (19)
- No cecal intubation and inadequate bowel preparation (70)

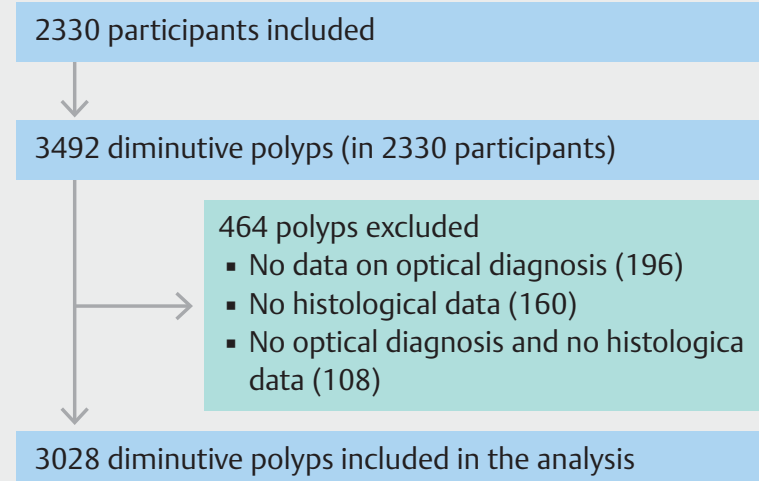

- Fig. 1 Flowchart of the included patients and polyps.

\section{Performance of optical diagnosis}

Optical diagnosis for diminutive adenomas in the colon and rectum showed a diagnostic accuracy of $76 \%$ (95\% Cl 74-77) compared to histological diagnosis. The NPV for adenomatous histology was $69 \%(95 \% \mathrm{Cl} 66-73)$ ( $\triangleright$ Table 3$)$.

In the rectosigmoid, a total of 1222 diminutive lesions were found, the NPV for adenomatous histology was $84 \%(95 \% \mathrm{Cl}$ $80-87)$. For hyperplastic polyps in the rectosigmoid the NPV was $76 \%$ (95\% Cl 73-78), the PPV was $61 \%$ (95\% Cl 56-66) and overall accuracy was $71 \%(95 \% \mathrm{Cl} 69-74)$ (

A total of 150 polyps in rectosigmoid (12.3\% of the total) were optically misdiagnosed as hyperplastic. In $5.1 \%$ and $1.9 \%$ of the cases, an adenoma or sessile serrated lesion, respectively, would have been left in place ( $5.3 \%$ other/no abnormality) ( Table 4).

For the optically misdiagnosed lesions ( $n=139 / 150$ photo documentation available), no significant difference was found with regard to use of IEE $(P=0.620)$.

Diagnostic accuracy for diminutive adenomas in the colon and rectum ranged from 74 to $78 \%(P=0.393)$ between the four endoscopy units and regarding hyperplastic lesions in the rectosigmoid diagnostic accuracy ranged from 70 to $73 \%(P=$ 0.769) ( Table 2).

Overall diagnostic accuracy between the 15 endoscopists ranged from $69 \%$ to $87 \%$. From 2576 polyps photo documentation was available. Image enhancement had been documented by endoscopy photos in $36.9 \%$, where in the majority of the cases I-scan was used. There was no significant difference between the use of IEE and the correct optical diagnosis for both

\begin{tabular}{|c|c|}
\hline Age (mean, SD), years & $68(5)$ \\
\hline Gender (female, $\mathrm{n}(\%)$ ) & $889(39)$ \\
\hline \multicolumn{2}{|l|}{ ASA Classification, n (\%) } \\
\hline . 1 & $801(34)$ \\
\hline .2 & $1441(62)$ \\
\hline .3 & $88(4)$ \\
\hline . 4 & $1(0)$ \\
\hline Boston Bowel Preparation Score (mean, SD) ${ }^{1}$ & $9(1)$ \\
\hline Cecal withdrawal time (mean, SD), minutes & $17(11)$ \\
\hline${ }^{1}$ Only patients with cecal intubation and BBPS $\geq 6$ & ded \\
\hline
\end{tabular}

adenomas in the colon and rectum $(P=0.612)$ and for hyperplastic polyps in the rectosigmoid $(P=0.842)$.

The sensitivity analysis to correct for clustering (i. e. multiple lesions per patient) showed similar results. (Data not shown.)

\section{Surveillance intervals}

In $>$ Table 5 results of the surveillance intervals are given. Surveillance intervals have been calculated at patient level, meaning that if only diminutive polyps were found the surveillance interval is based on optical diagnosis solely, whereas if additional polyps (>5 mm) were found, the histology of these non-diminutive polyps determined the surveillance intervals. For the "resect and discard" strategy agreement for the Dutch, European, and American guidelines was $90.6 \%, 91.2 \%$ and $90.9 \%$ respectively. Approximately $6.0 \%$ would have received a shorter surveillance interval based on optical diagnosis, while in $2.8 \%$ to $3.3 \%$ of the cases a longer surveillance interval would have been recommended.

A detailed overview of the surveillance intervals for the "resect and discard" and "diagnose and leave in place" strategies using different guidelines is presented in Supplementary Table 1 and Supplementary Table 2.

\section{Discussion}

We have evaluated the accuracy of optical diagnosis of diminutive polyps, as well as the scenarios for "resect and discard" and "diagnose and leave" in the clinical endoscopy practice setting of the Bowel Cancer Screening Program (BCSP) in the Netherlands. Optical diagnosis of diminutive adenomatous polyps in the rectosigmoid showed $72 \%$ diagnostic accuracy and $84 \%$ NPV: thus, the PIVI thresholds were not met.

When applying the "resect and discard" scenario, agreement on surveillance intervals between optical and histological diagnosis applying the Dutch, European and American surveillance guidelines was $90.6 \%, 91.2 \%$ and $90.9 \%$ respectively. Therefore, at group level, the PIVI thresholds ( $\geq 90 \%$ agreement) concerning surveillance strategies were met.

Given the substantial amount of research focusing on optical diagnosis and the potential cost savings, this is an important 
- Table 2 Endoscopic and histologic characteristics of diminutive lesions and accuracy per center.

\begin{tabular}{|c|c|c|}
\hline & Lesions in colon and rectum & Lesions in rectosigmoid \\
\hline Number of diminutive lesions & 3028 & 1222 \\
\hline Polyp size (mean, SD) in mm & $4(1)$ & $4(1)$ \\
\hline \multicolumn{3}{|l|}{ Polyp size (n, \%) } \\
\hline . $1-2 \mathrm{~mm}$ & $544(18)$ & $192(16)$ \\
\hline . $3-5 \mathrm{~mm}$ & $2484(82)$ & $1030(84)$ \\
\hline \multicolumn{3}{|l|}{ Paris classification (n, \%) ${ }^{1}$} \\
\hline. Ip & $235(8)$ & $118(10)$ \\
\hline . Is & $2477(82)$ & $985(81)$ \\
\hline - lia & $264(9)$ & $95(8)$ \\
\hline - lib & $15(0)$ & $4(0)$ \\
\hline - Unclassified & $37(1)$ & $20(1)$ \\
\hline \multicolumn{3}{|l|}{ Histology (n, \%) } \\
\hline - Adenoma & $2038(67)$ & $602(49)$ \\
\hline - Tubular & 1964 & 572 \\
\hline - Villous & 1 & 1 \\
\hline - Tubulovillous & 73 & 29 \\
\hline - Sessile serrated lesion or traditional serrated adenoma & $106(4)$ & $41(3)$ \\
\hline - Hyperplastic polyp & $563(19)$ & $439(36)$ \\
\hline - Carcinoma & $3(0)$ & $2(0)$ \\
\hline - Other finding & $99(3)$ & $48(4)$ \\
\hline - No abnormality & $222(7)$ & $92(8)$ \\
\hline \multicolumn{3}{|l|}{ Dysplasia (n, \%) } \\
\hline \multicolumn{3}{|l|}{ For adenomas } \\
\hline - Low-grade dysplasia & $2022(99.2)$ & $589(97.8)$ \\
\hline - High-grade dysplasia & $15(0.7)$ & $12(2.0)$ \\
\hline - Unclassified & $1(0.1)$ & $1(0.2)$ \\
\hline \multicolumn{3}{|l|}{ For sessile serrated lesions } \\
\hline - With dysplasia & $31(29.2)$ & $10(24.4)$ \\
\hline " Without dysplasia & $71(67.0)$ & $30(73.2)$ \\
\hline - Unclassified & $4(3.8)$ & $1(2.4)$ \\
\hline $\begin{array}{l}\text { Diagnostic accuracy per endoscopy center } \\
\text { (n of polyps, \% correctly estimated lesions) }\end{array}$ & Adenomas in colon and rectum & Hyperplastic polyps in rectosigmoid \\
\hline - Center $1^{2}$ & $839(77)$ & $339(72)$ \\
\hline - Center $2^{2}$ & $1007(74)$ & $397(70)$ \\
\hline - Center $3^{2}$ & $928(77)$ & $386(73)$ \\
\hline - Center $4^{2}$ & $254(76)$ & $100(70)$ \\
\hline
\end{tabular}


- Table 3 Optical diagnosis versus histological evaluation of diminutive polyps. ${ }^{1}$

\begin{tabular}{|c|c|c|}
\hline \multicolumn{3}{|l|}{ Lesions in colon and rectum $(n=3028)$} \\
\hline & Adenomas $(n=2038)^{2}$ & Hyperplastic polyps $(n=563)^{2}$ \\
\hline Overall accuracy $(95 \% \mathrm{Cl})$ & $76 \%(74-77)$ & $79 \%(77-80)$ \\
\hline Sensitivity $(95 \% \mathrm{Cl})$ & $90 \%(88-91)$ & $48 \%(44-53)$ \\
\hline Specificity $(95 \% \mathrm{Cl})$ & $47 \%(44-50)$ & $85 \%(84-87)$ \\
\hline Positive Predictive Value (PPV) (95\% Cl) & $78 \%(76-79)$ & $43 \%(39-47)$ \\
\hline Negative Predictive Value (NPV) $(95 \% \mathrm{Cl})$ & $69 \%(66-73)$ & $88 \%(86-89)$ \\
\hline \multicolumn{3}{|l|}{ Lesions in the rectosigmoid $(n=1222)$} \\
\hline & Adenomas $(n=602)^{2}$ & Hyperplastic polyps $(n=439)^{2}$ \\
\hline Overall accuracy $(95 \% \mathrm{Cl})$ & $72 \%(69-74)$ & $71 \%(69-74)$ \\
\hline Sensitivity (95\% Cl) & $89 \%(86-92)$ & $54 \%(49-59)$ \\
\hline Specificity $(95 \% \mathrm{Cl})$ & $55 \%(51-59)$ & $81 \%(78-84)$ \\
\hline Positive Predictive Value (PPV) $(95 \% \mathrm{Cl}$ ) & $66 \%(62-69)$ & $61 \%(56-66)$ \\
\hline Negative Predictive Value (NPV) (95\% Cl) & $84 \%(80-87)$ & $76 \%(73-78)$ \\
\hline
\end{tabular}

- Table 4 Specification of the polyps incorrectly estimated as hyperplastic polyp in the rectosigmoid region.

\begin{tabular}{|c|c|c|c|}
\hline $\begin{array}{l}\text { Pathology } \\
\text { evaluation }\end{array}$ & Number & $\begin{array}{l}\% \text { from in- } \\
\text { correctly } \\
\text { estimated } \\
\text { hyperplas- } \\
\text { tic polyps }\end{array}$ & $\begin{array}{l}\text { \% from total } \\
\text { polyps in } \\
\text { rectosig- } \\
\text { moid }\end{array}$ \\
\hline Total & $150^{1}$ & $100 \%$ & $12.3 \%$ \\
\hline Adenoma & 62 & \multirow[t]{4}{*}{$41.3 \%$} & \multirow[t]{4}{*}{$5.1 \%^{2}$} \\
\hline - Tubular & 59 & & \\
\hline - Villous & 0 & & \\
\hline - Tubulovillous & 3 & & \\
\hline Serrated lesions & 23 & \multirow[t]{3}{*}{$15.3 \%$} & \multirow[t]{3}{*}{$1.9 \%^{2}$} \\
\hline $\begin{array}{l}\text { - Sessile serrated } \\
\text { lesion }\end{array}$ & 22 & & \\
\hline $\begin{array}{l}\text { - Traditional } \\
\text { serrated adenoma }\end{array}$ & 1 & & \\
\hline Other & 23 & \multirow[t]{4}{*}{$15.3 \%$} & \multirow[t]{4}{*}{$1.9 \%$} \\
\hline - Inflammatory polyp & 20 & & \\
\hline - Leiomyoma & 1 & & \\
\hline - B-cell lymphoma & 2 & & \\
\hline No abnormality & 42 & $28.0 \%$ & $3.4 \%$ \\
\hline \multicolumn{4}{|c|}{$\begin{array}{l}{ }^{1} \mathrm{~A} \text { total of } 150 \text { polyps in rectosigmoid ( } 12.3 \% \text { of the total) were optically } \\
\text { misdiagnosed as hyperplastic. }\end{array}$} \\
\hline
\end{tabular}

- Table 5 Surveillance intervals based on optical diagnosis vs. histology, according to different guidelines (NL, EU, USA) and applying the "resect and discard" scenario.

\begin{tabular}{|c|c|c|c|}
\hline & \multicolumn{3}{|c|}{$\begin{array}{l}\text { Resect and discard strategy } \\
\text { (Optical diagnosis for adenomatous polyps in the } \\
\text { entire colon) } \\
\mathrm{N}=2330 \text { patients }\end{array}$} \\
\hline & $\begin{array}{l}\text { Agreement between } \\
\text { optical diagnosis and } \\
\text { histology }\end{array}$ & $\begin{array}{l}\text { Surveillance } \\
\text { earlier }\end{array}$ & $\begin{array}{l}\text { Surveil- } \\
\text { lance } \\
\text { later }^{1}\end{array}$ \\
\hline $\begin{array}{l}\text { Dutch } \\
\text { guideline }\end{array}$ & $\begin{array}{l}90.6 \% \\
N=2110\end{array}$ & $\begin{array}{l}6.2 \% \\
N=144\end{array}$ & $\begin{array}{l}3.3 \% \\
N=76\end{array}$ \\
\hline $\begin{array}{l}\text { European } \\
\text { guideline }\end{array}$ & $\begin{array}{l}91.2 \% \\
N=2126\end{array}$ & $\begin{array}{l}5.9 \% \\
N=137\end{array}$ & $\begin{array}{l}2.9 \% \\
N=67\end{array}$ \\
\hline $\begin{array}{l}\text { American } \\
\text { guideline }\end{array}$ & $\begin{array}{l}90.9 \% \\
N=2119\end{array}$ & $\begin{array}{l}6.2 \% \\
N=145\end{array}$ & $\begin{array}{l}2.8 \% \\
N=66\end{array}$ \\
\hline \multicolumn{4}{|c|}{$\begin{array}{l}{ }^{1} \text { This includes also the patients who receive no surveillance according to } \\
\text { optical diagnosis. The number of patients who would receive no surveil- } \\
\text { lance are for the Dutch guideline } 36 / 76 \text { patients, for the European guide- } \\
\text { line } 36 / 67 \text { patients and according to the American quideline } 4 / 66 \text {. }\end{array}$} \\
\hline
\end{tabular}

and clinically relevant topic $[17,18]$. However, results of studies assessing optical diagnosis of small and diminutive polyps vary considerably. So far, data have been obtained predominantly in well controlled study settings, where endoscopists were additionally trained in recognition and characterization of lesions and had been instructed on the systematic use of image-enhancement. Baseline characteristics of the diminutive lesions in our study are within the range of variation reported in recent 
literature, and are therefore representative for national and global data $[19,20]$.

When evaluating published data from additionally trained endoscopists, the NPV for optical diagnosis of adenomas in the rectosigmoid varies from $82.0 \%$ to $94.7 \%$ in studies where narrow-band imaging (NBI) was used [21]. Ladabaum et al. [22] showed that while only $25 \%$ of the trained endoscopists used $\mathrm{NBI}$, polyps were assessed with over $90 \%$ accuracy.

Image enhancement for optical diagnosis of diminutive polyps is considered to be beneficial, but remains an item of discussion since several studies have not shown significant differences in accuracy for optical diagnosis with image enhancement compared to HD-WLE [23-25]. In our study, reflecting daily endoscopy practice, use of image-enhancement in addition to HD-WLE was left at the discretion of the endoscopist. In $36.9 \%$ use of image-enhancement was photo-documented and no significant differences were found in optical diagnosis with or without use of IEE.

Experience and additional training of endoscopists may substantially add to accuracy of optical diagnosis. Endoscopists working in academic centers obtain better results in optical diagnosis compared to endoscopists working in community practices [22]. Indeed, in a surveillance setting in non-academic centers without additional training, Kuiper et al. [26] noted low sensitivity $(77.0 \%)$ and specificity $(78.8 \%)$ for optical diagnosis.

In our study, performance of academic and regional centers with respect to optical diagnosis was in the same range. Concerning surveillance intervals, in previous studies, 19\% inaccuracy in determining surveillance intervals based on optical diagnosis has been reported [26]. It should be noted that surveillance intervals were calculated on patient level, therefore, all polyps (diminutive but also larger polyps) were taken into account, taking into account that intervals are affected mostly by the larger polyps. Therefore, optical misdiagnosis of smaller polyps can be overruled by the presence of larger polyps. This raises the question whether surveillance interval is the most appropriate criterium when deciding on diminutive polyps. It does however perfectly represent the impact of the guidelines used in current clinical practice.

A recent Dutch study from Vleugels et al. has shown that at group level in a selected population of endoscopists after additional training, optical diagnosis of diminutive polyps (with high-confidence) in the Dutch FIT-based CRC screening setting using narrow-band imaging (NBI) met the ASGE PIVI thresholds [20]. However, at individual level, only $59 \%$ of the additionally trained endoscopists did meet these PIVI thresholds.

These authors showed that selected endoscopists, additionally trained by a validated training module on NICE [27] and WASP [28] were able to diagnose neoplastic lesions (with highconfidence) using NBI in the rectosigmoid with pooled NPVs of more than $90 \%$ [20]. In addition, they were also able to accurately recommend surveillance intervals based on optical diagnosis [20]. When interpreting these data, it should be noted that these endoscopists represent an expert group, of which endoscopists were only allowed to participate after passing an additional exam ( $\geq 90 \%$ diagnostic accuracy (same as in PIVI))
[20]. Therefore, the results of that study cannot be extrapolated directly to community practice. On the other hand, Vleugels et al. [20] have clearly shown that optical diagnosis may become feasible in a special setting in which endoscopist training and feedback is incorporated.

In a study by Schachschal et al. performed in a screening setting, optical diagnosis had an accuracy of only $71.1 \%$ and NPV of $59.3 \%$ [29]. Our results compare favorably with that study with NPV for hyperplastic polyps in the rectosigmoid and for adenomas in the colon of respectively $76 \%$ and $69 \%$. The agreement on surveillance intervals in our study reached an accuracy of over $90 \%$, while data from the Schachschal et al. study cannot be retrieved from the manuscript [29].

To implement these strategies in clinical practice, costs should be considered. Using simulation modelling, optical diagnosis in the Dutch BCSP appears to save costs without decreasing program effectiveness when compared with current histology analysis of all diminutive polyps [30]. In line with these modelling data, Hassan et al. have already shown that the "resect and discard" strategy for diminutive polyps detected during screening indeed results in economic benefit without impact on program efficacy [6]. Applying these strategies may not only result in cost savings but also in a reduction of risks of polypectomies and of patient discomfort.

If lesions are left in situ (i. e. "diagnose and leave"' scenario), an incorrect optical diagnosis may have significant impact. In our study twelve percent of the rectosigmoid lesions was estimated as hyperplastic but contained other histology (i. e. adenomas and serrated polyps). When the lesions are removed (i.e. "resect and discard" scenario), the impact of incorrect optical diagnosis is limited.

High-risk lesions found in our study (3 carcinomas and 15 lesions with high-grade dysplasia) should be considered carefully. Here, evaluation of treatment and resection margins is of importance, and they should receive stricter follow-up.

Several strengths of our study need to be acknowledged. First, we evaluated the efficacy of the optical diagnosis strategy within a) the structured setting of the nationwide Bowel Cancer Screening Program b) regular endoscopy practices where all participating endoscopists were qualified and accredited for performing colonoscopies for the Dutch FIT-based BCSP [12], but without additional training or selection for competency in optical diagnosis. We prospectively collected data from four endoscopy units (both academic and regional) in South Limburg (the Netherlands). The results therefore reflect daily clinical practice in the Netherlands in the first years of implementation of the BCSP.

Several limitations need to be acknowledged as well. Since standardized endoscopy reports are used for data collection, some detailed information is lacking. Therefore, the results of this study should be interpreted with caution. First, the level of confidence with which an endoscopist rates his/her optical diagnosis is relevant. A meta-analysis from 2015 showed that estimations with high-confidence are more likely to be correct [7]. In our real-life study endoscopists neither were asked for nor included the level of confidence in the standard endoscopy-report and we were therefore not able to assess the level 
of confidence for optical diagnosis. Second, image-enhancement was used upon discretion of the endoscopist, but the specific use per polyp was not reported. Based on photo-documentation, image-enhancement was used in at least $36.9 \%$ of endoscopies.

To improve performance and to allow implementation of optical diagnosis in the setting of a national BCSP, essential steps need to be taken: 1) for equipment, standard use of high-definition white light endoscopy with additional image enhancement; 2) for endoscopists, additional training and monitoring of individual performance; 3 ) standard use of optical classification systems (e.g. NICE or WASP); 4) inclusion of "the level of confidence in optical diagnosis" of the endoscopist in the optical diagnosis algorithm; and 5) photo documentation and archiving [31,32].

Implementation of optical diagnosis strategy in clinical practice remains challenging [31]. A simplified approach has been suggested by Atkinson and East [33]; the DISCARD-lite strategy where all diminutive polyps proximal to rectosigmoid junction are assumed premalignant and therefore "resect and discard" is applied, while hyperplastic polyps in the rectosigmoid can be left in situ. A recent study by von Renteln et al. indicates that this simplified combined optical and location-based strategy may help to overcome current challenges in the implementation of the 'resect and discard' strategy [34].

In the near future an important role for artificial intelligence (Al) in optical detection and characterization of diminutive polyps is foreseen, thus reducing or even eliminating endoscopist inter-observer variability. Several computer-aided detection and characterization systems and algorithms are being developed with promising preliminary data such as a NPV for identification and classification of diminutive rectosigmoid adenomas ranging from $91.5 \%$ to $97 \%$ [35-38]. More extensive research in larger clinical trial settings is necessary to confirm and expand on these results.

Based on our data from regular endoscopy care in the bowel cancer screening program, we cannot recommend leaving diminutive rectosigmoid polyps in place. On the other hand, the thresholds for the "resect and discard" strategy, i. e. agreement on post-polypectomy surveillance intervals were met. Implementation of this strategy can therefore be considered. These results, however, need to be validated, in a setting where the above mentioned steps have been implemented (i.e. standardized and structural use of level of confidence and use of IEE).

\section{Conclusion}

To conclude, our study representing current clinical practice in the Dutch BCSP practice on optical diagnosis of diminutive polyps showed that accuracy of predicting histology remains challenging, and risk of incorrect optical diagnosis is significant. Therefore, it is too early to safely implement these strategies. It remains to be determined whether optical diagnosis will structurally meet the PIVI criteria in routine clinical endoscopy practices.

\section{Competing interests}

\section{Disclosures:}

R.M.M. Bogie: received an educational grant from Pentax Medical Europe.

E. Dekker: I have endoscopic equipment on loan of FujiFilm, receive a research grant from FujiFilm. I have received a honorarium for consultancy from FujiFilm, Olympus, Tillots, GI Supply and CPP-FAP and a speakers' fee from Olympus,

Roche and GI Supply. Besides, I am in the supervisory board of eNose.

A.A.M. Masclee: 1. Funding grant from Pentax International $\mathrm{GMBH}$. 2. Project funding from Dutch Cancer Society.

S. Sanduleanu-Dascalescu: received a research grant from Pentax Europe.

\section{References}

[1] Edwards BK, Ward E, Kohler BA et al. Annual report to the nation on the status of cancer, 1975-2006, featuring colorectal cancer trends and impact of interventions (risk factors, screening, and treatment) to reduce future rates. Cancer 2010; 116: 544-573

[2] Lieberman DA, Rex DK, Winawer S] et al. Guidelines for colonoscopy surveillance after screening and polypectomy: a consensus update by the US Multi-Society Task Force on Colorectal Cancer. Gastroenterology 2012; 143: 844-857

[3] von Karsa L, Patnick J. European Colorectal Cancer Screening Guidelines Working Group. et al. European guidelines for quality assurance in colorectal cancer screening and diagnosis: overview and introduction to the full supplement publication. Endoscopy 2013; 45: 51-59

[4] Shaukat A, Mongin S], Geisser MS et al. Long-term mortality after screening for colorectal cancer. N Engl J Med 2013; 369: 1106-1114

[5] Toes-Zoutendijk E, van Leerdam ME, Dekker E et al. Real-time monitoring of results during first year of dutch colorectal cancer screening program and optimization by altering fecal immunochemical test cutoff levels. Gastroenterology 2017; 152: 767-775 e762

[6] Hassan C, Pickhardt PJ, Rex DK. A resect and discard strategy would improve cost-effectiveness of colorectal cancer screening. Clin Gastroenterol Hepatol 2010; 8: 865-869, 869 e861-863

[7] ASGE Technology Committee. Abu Dayyeh BK, Thosani N et al. ASGE Technology Committee systematic review and meta-analysis assessing the ASGE PIVI thresholds for adopting real-time endoscopic assessment of the histology of diminutive colorectal polyps. Gastrointest Endosc 2015; 81: 502 e501-502 e516

[8] Rex DK, Kahi C, O’Brien M et al. The American Society for Gastrointestinal Endoscopy PIVI (Preservation and Incorporation of Valuable Endoscopic Innovations) on real-time endoscopic assessment of the histology of diminutive colorectal polyps. Gastrointest Endosc 2011 73: 419-422

[9] le Clercq CM, Bouwens MW, Rondagh EJ et al. Postcolonoscopy colorectal cancers are preventable: a population-based study. Gut 2014; 63: 957-963

[10] Rondagh EJ, Bouwens MW, Riedl RG et al. Endoscopic appearance of proximal colorectal neoplasms and potential implications for colonoscopy in cancer prevention. Gastrointest Endosc 2012; 75: 1218 1225

[11] (RIVM) RvVeM. Protocol voor de toelating en auditing van coloscopiecentra en endoscopisten - Bevolkingsonderzoek Darmkanker. 2012: https://www.rivm.nl/documenten/protocol-toelating-en-auditing-coloscopiecentra-endoscopisten 
[12] Bronzwaer MES, Depla A, van Lelyveld N et al. Quality assurance of colonoscopy within the Dutch national colorectal cancer screening program. Gastrointest Endosc 2019; 89: 1-13

[13] Calderwood AH, Schroy PC 3rd, Lieberman DA et al. Boston Bowel Preparation Scale scores provide a standardized definition of adequate for describing bowel cleanliness. Gastrointest Endosc 2014; 80 : 269-276

[14] Schlemper RJ, Riddell RH, Kato Y et al. The Vienna classification of gastrointestinal epithelial neoplasia. Gut 2000; 47: 251-255

[15] NVMDL (Dutch Association of Gastroenterology) - Dutch Guideline Colonoscopy Surveillance 2013

[16] Hassan C, Quintero E, Dumonceau JM et al. Post-polypectomy colonoscopy surveillance: European Society of Gastrointestinal Endoscopy (ESGE) Guideline. Endoscopy 2013; 45: 842-851

[17] Lieberman D, Moravec M, Holub J et al. Polyp size and advanced histology in patients undergoing colonoscopy screening: implications for CT colonography. Gastroenterology 2008; 135: 1100-1105

[18] Von Renteln D, Bouin M, Barkun AN. Current standards and new developments of colorectal polyp management and resection techniques. Expert Rev Gastroenterol Hepatol 2017; 11: 835-842

[19] Vleugels JLA, Hassan C, Senore C et al. Diminutive polyps with advanced histologic features do not increase risk for metachronous advanced colon neoplasia. Gastroenterology 2019; 156: 623-634 e623

[20] Vleugels JLA, Dijkgraaf MGW, Hazewinkel Y etal. Effects of training and feedback on accuracy of predicting rectosigmoid neoplastic lesions and selection of surveillance intervals by endoscopists performing optical diagnosis of diminutive polyps. Gastroenterology 2018; 154: 1682-1693

[21] Ignjatovic A, East JE, Suzuki $\mathrm{N}$ et al. Optical diagnosis of small colorectal polyps at routine colonoscopy (Detect InSpect ChAracterise Resect and Discard; DISCARD trial): a prospective cohort study. Lancet Oncol 2009; 10: 1171-1178

[22] Ladabaum U, Fioritto A, Mitani A et al. Real-time optical biopsy of colon polyps with narrow band imaging in community practice does not yet meet key thresholds for clinical decisions. Gastroenterology 2013; 144: 81-91

[23] Rees C], Rajasekhar PT, Wilson A et al. Narrow band imaging optical diagnosis of small colorectal polyps in routine clinical practice: the Detect Inspect Characterise Resect and Discard 2 (DISCARD 2) study. Gut 2017; 66: 887-895

[24] Klare P, Haller B, Wormbt S et al. Narrow-band imaging vs. high definition white light for optical diagnosis of small colorectal polyps: a randomized multicenter trial. Endoscopy 2016; 48: 909-915

[25] Basford PJ, Longcroft-Wheaton G, Higgins B et al. High-definition endoscopy with i-Scan for evaluation of small colon polyps: the HiSCOPE study. Gastrointestinal endoscopy 2014; 79: 111-118
[26] Kuiper T, Marsman WA, Jansen JM et al. Accuracy for optical diagnosis of small colorectal polyps in nonacademic settings. Clin Gastroenterol Hepatol 2012; 10: 1016-1020; quiz e1079

[27] Repici A, Ciscato C, Correale L et al. Narrow-band Imaging International Colorectal Endoscopic Classification to predict polyp histology: REDEFINE study (with videos). Gastrointest Endosc 2016; 84: 479486 e 473

[28] JE IJ, Bastiaansen BA, van Leerdam ME et al. Development and validation of the WASP classification system for optical diagnosis of adenomas, hyperplastic polyps and sessile serrated adenomas/polyps. Gut 2016; 65: 963-970

[29] Schachschal G, Mayr M, Treszl A et al. Endoscopic versus histological characterisation of polyps during screening colonoscopy. Gut 2014; 63: 458-465

[30] Vleugels JLA, Greuter MJE, Hazewinkel Y et al. Implementation of an optical diagnosis strategy saves costs and does not impair clinical outcomes of a fecal immunochemical test-based colorectal cancer screening program. Endosc Int Open 2017; 5: E1197-E1207

[31] Kaltenbach T, Rex DK, Wilson A et al. Implementation of optical diagnosis for colorectal polyps: standardization of studies is needed. Clin Gastroenterol Hepatol 2015; 13: 6-10 e11

[32] Kaminski MF, Hassan C, Bisschops R et al. Advanced imaging for detection and differentiation of colorectal neoplasia: European Society of Gastrointestinal Endoscopy (ESGE) Guideline. Endoscopy 2014; 46: 435-449

[33] Atkinson NS, East JE. Optical biopsy and sessile serrated polyps: Is DISCARD dead? Long live DISCARD-lite! Gastrointest Endosc 2015; 82: $118-121$

[34] von Renteln D, Kaltenbach T, Rastogi A et al. Simplifying resect and discard strategies for real-time assessment of diminutive colorectal polyps. Clin Gastroenterol Hepatol 2018; 16: 706-714

[35] Mori Y, Kudo SE, Misawa M et al. Real-time use of artificial intelligence in identification of diminutive polyps during colonoscopy: a prospective study. Ann Intern Med 2018; 169: 357-366

[36] Byrne MF, Chapados N, Soudan F et al. Real-time differentiation of adenomatous and hyperplastic diminutive colorectal polyps during analysis of unaltered videos of standard colonoscopy using a deep learning model. Gut 2017: doi:10.1136/gutjnl-2017-314547

[37] Chen PJ, Lin MC, Lai M] et al. Accurate Classification of diminutive colorectal polyps using computer-aided analysis. Gastroenterology 2018; 154: 568-575

[38] Vinsard DG, Mori Y, Misawa M et al. Quality assurance of computeraided detection and diagnosis in colonoscopy. Gastrointest Endosc 2019; 90: 55-63 